\title{
PERCEPÇÃO DOS ESTUDANTES EM RELAÇÃO A UMA EXPERIÊNCIA DE GAMIFICAÇÃO NA DISCIPLINA DE PSICOLOGIA E EDUCAÇÃO INCLUSIVA
}

\author{
E. J. COHEN ${ }^{1}$, P. E. G. A. DELAGE ${ }^{2}$, R. B. ALENCAR ${ }^{3}$ e A. B. MENEZES ${ }^{4}$ \\ Universidade Federal do Pará \\ alinebcm@gmail.com ${ }^{4}$
}

Submetido em 07/08/2018 e aceito em 14/02/2020

DOI: $10.15628 /$ holos.2020.7597

\section{RESUMO}

O objetivo deste trabalho foi avaliar a percepção de discentes de uma disciplina de Psicologia e Educação Inclusiva sobre uma atividade gamificada adotada com a expectativa de estimular o engajamento dos alunos e a aproximação deles com a prática sem sair da sala de aula. No contexto educacional, a utilização da Gamificação pode promover a aprendizagem, aumentar a motivação dos alunos e a autonomia, por se tratar de uma proposta que exige participação ativa. A pesquisa se constitui de uma amostra de 35 alunos, e a utilização de um questionário semi-estruturado, com 20 questões cujo os itens utilizaram uma escala likert de 5 pontos, variando de "Discordo Totalmente" a "Concordo Totalmente", além de uma questão aberta. Para analisar as questões foi calculado o Ranking Médio Individual (RM) dos itens de escala likert e depois a média aritmética entre os RM que constitui cada uma das três categorias que estavam sendo investigadas. Os resultados obtidos através da análise dos questionários mostraram que a atividade proposta teve efeitos positivos no engajamento dos alunos, estimulando neles a autonomia em relação ao seu próprio processo de aprendizagem. A pesquisa também mostrou que a atividade foi positiva em aproximar os alunos com a prática do psicólogo no ambiente escolar, juntando teoria e sua aplicação.

PALAVRAS-CHAVE: Gamificação, metodologias ativas, processo do incidente, Role Playing Game, inclusão.

\section{STUDENTS PERCEPTION ABOUT A GAMIFICATION EXPERIENCE IN THE PSYCHOLOGY AND INCLUSIVE EDUCATION SUBJECT}

\section{ABSTRACT}

This paper presents the use of a gamificated activity applied to a subject of Psychology an Inclusive Education and analyses the effectiveness of using game elements to stimulate student's engagement and their proximity to the practice without leaving the classroom. In educational context, gamification may promote learning, increase student motivation and autonomy, by demanding active participation. This research was made with the participation of 35 students through the application of a semi-structured questionnaire with 20 questions using a 5 point linkert scale, varying from
\end{abstract}

"totally disagree" to "totally agree" and an open question. To analyze the questions an Individual Medium Ranking (RM) was created and then was calculated the arithmetic media among the RM of three different categories. The results have shown that the proposed activity had positive effect upon student engagement, stimulating their autonomy toward their own learning process. The research also has shown that the activity was positive for approximating students with the school psychology practice, combining theory and its application.

KEYWORDS: Gamification, active learning, incident process, role playing game, inclusion. 


\section{INTRODUÇÃO E REFERÊNCIAL BIBLIOGRÁFICO}

O modelo de ensino formal ainda vigente baseia sua importância em passar para o aluno o conteúdo programático e trata o aprendiz como receptor de informações. Fortunato e Teichner (2017) denominam isso de "perspectiva utilitária", a partir da qual "a escola valoriza o seu resultado (aprovação em vestibular, nota alta em exame nacional, emprego, concurso público etc.)" (p. 381). De acordo com Quinaud e Baldessar (2017), a educação do século XXI não pode ser restrita à apresentação de fatos, os quais são facilmente acessíveis de outras formas. Deve-se, assim, discutir o que pode ser feito com tais fatos. Martins (2013) destaca que:

é preciso perceber que enquanto o mundo do lado de fora da escola está fervilhando em informações, barulho e agitação, ainda hoje se espera uma escola com salas de aula paradas, silenciosas, com carteiras enfileiradas, de preferência sem que haja comunicação entre os alunos durante as aulas (p. 162).

O estudante, ao ingressar no ensino superior, já traz consigo o modelo escolar que põe o professor responsável por organizar e transmitir conhecimento. Por outro lado, o professor espera que seu novo aluno seja mais participativo e questionador, jogando a responsabilidade da falta de motivação sobre o aluno, enquanto o mesmo responsabiliza o professor e sua didática por não motivá-los (Gil, Garcia, Lino \& Gil, 2017). Segundo estes autores, a qualidade do ensino depende do tripé: Estrutura, Docente e Discente, e é necessário compreender como estes fatores se relacionam na prática pedagógica. Entender este tripé é fundamental para o ensino superior, e é importante que a Universidade proporcione ao aluno estrutura necessária para aprendizado, assim como também é importante que os professores busquem meios para que a aprendizagem ocorra de forma dinâmica e significativa, recorrendo a metodologias diferentes e construam uma relação de afetividade com os alunos. Diogo et al. (2016) e Tontini e Walter (2014), inclusive apontam que fatores de natureza pedagógica, como dificuldades de aprendizagem e a relação aluno-professor, podem contribuir para a evasão universitária.

Maluf (2016) diz que alternativas pedagógicas podem ser usadas em todos os níveis de educação e que elas ajudam os alunos na construção do seu próprio conhecimento. Segundo este autor, para que uma atividade pedagógica alternativa seja eficaz, ela precisa ser organizada de forma que: "(1) apontem os objetivos claros para os profissionais de aprendizagem e o aprendiz; 2) abarquem atividades significativas; 3) suscitem participação ativa do aprendiz; 4) reconheçam as necessidades especificas de desenvolvimento do aprendiz; 5) atendam os interesses do profissional" (p. 24).

Dentre diversas estratégias pedagógicas que têm sido propostas, encontra-se a gamificação. Com base no trabalho de Karl Kapp (2012, como citado em Borges et al., 2013) a gamificação pode ser definida como "a aplicação de elementos utilizados no desenvolvimento de jogos eletrônicos, tais como estética, mecânica e dinâmica, em outros contextos não relacionados a jogos" (p. 235). O termo já é utilizado desde 2002, quando foi cunhado por Pelling (2011), e vem ganhando popularidade desde então. Mcgonigal (2010), apesar de não utilizar o termo gamificação, aborda o assunto e discute diversas possibilidades e modelos de aplicação. 
Losso e Borges (2015), afirmam que, por ser um termo novo em educação, muitos tendem a confundir gamificação com o próprio uso de games eletrônicos ou o uso de jogos educativos em sala de aula. Segundo Seixas, Gomes, Melo Filho e Rodrigues (2014) "não se pretende ensinar com jogos ou através de jogos, mas sim usar a mecânica dos jogos como forma de promover a motivação e o engajamento dos alunos" (p. 561). A ênfase que tem sido atribuída à gamificação decorre, entre outros fatores, da elevada inserção de games no cotidiano atual e pelo seu caráter de motivação intrínseca, isto é, o jogo promove a motivação em continuar jogando (Fortunato \& Teichner, 2017).

De acordo com a revisão de literatura realizada por Borges et al. (2013), apesar de o uso de jogos na educação não ser novidade, as primeiras publicações sobre gamificação em contextos educacionais foram encontradas em 2011. De acordo com o levantamento dos autores, este interesse tem sido crescente, especialmente no ensino superior, sendo que em todos os trabalhos encontrados, uma das justificativas apresentadas para o uso da gamificação era favorecer a motivação estudantil. Para de Paula e Fávero (2016), o game design poderia ser utilizado como uma "ferramenta de modificação do ensino" (p. 1460). Isso implicaria em ambientes de aprendizagem que apresentem dilemas complexos e desafios emocionantes, promovendo pensamento crítico, resolução criativa de problemas e cooperação (de Quadros, 2015).

Para tal, como afirmam, Quinaud e Baldessar (2017), a gamificação não pode ser resumida à inserção de elementos soltos de jogos, devendo considerar "toda a experiência do indivíduo" a partir de "uma sistemática para a resolução de problemas" (p. 218). Neste sentido, Fardo (2013) define jogo como "um sistema em que os jogadores se envolvem em um desafio abstrato, definido por regras, interatividade e feedback, que resulta em uma saída quantificável e frequentemente provoca uma reação emocional" (p. 43). Em todos os jogos é possível notar características comuns: 1) o jogo possui Metas; 2) o jogo possui Regras; 3) é necessário que a participação dele seja voluntária e 4) o jogo possui um sistema de feedback, mostrando quase que instantaneamente as consequências de suas ações (McGonigal, 2012).

Algumas ferramentas de jogos que têm sido utilizadas em iniciativas gamificadas são: pontos; níveis; rankings; desafios e missões; medalhas e conquistas; integração; loops de engajamento; personalização; reforço e feedback; regras; e narrativas (Orlandi, Duque, Mori \& Orlandi, 2018). Para alguns autores, como Martins, Nery Filho, Vieira e Pontes (2014), o feedback claro, justo e imediato seria a principal característica a ser destacada no ambiente escolar, por possibilitar ao aprendiz a compreensão de seus erros e a realização de novas tentativas.

Aplicando o conceito de gamificação aos planos de aula, Fortunato e Teichner (2017) afirmam que as mecânicas dos jogos seriam incorporadas nos componentes específicos da atividade proposta, que coletivamente constituiriam a dinâmica do jogo. Além disso, a estética do jogo (seu "conteúdo sensorial", p. 383) seria fundamental para o envolvimento emocional do jogador. Deste modo, o professor poderia organizar o conteúdo em desafios progressivos (o chamado "ciclo de progressão", p. 383), os quais devem ser seguidos por feedbacks que impulsionem um novo ciclo. $O$ desafio seria manter o estudante engajado no enfrentamento dos desafios. Para tal, os autores propõem a construção da narrativa como elemento motivador. "A narrativa consiste na elaboração de um enredo que envolva e dê sentido ao jogo, (...) é importante, pois permite que componentes de um jogo sejam valorizados de forma interna, sem utilizar algum 
fator externo" (p. 385). A importância da narrativa também é destacada por Martins et al. (2014), que recomendam que a mesma seja atraente, inteligente e coerente.

O uso da gamificação no contexto educacional tem recebido críticas, em especial pelo incentivo à competição, o que poderia favorecer o desenvolvimento de padrões de comportamento indesejáveis como falta de ética e de cooperação (Deterding, 2011, como citado em Orlandi et al., 2018). Outras críticas referem-se ao risco de ou tornar o jogo "chato" pela sua finalidade educacional, ou perder o foco do processo de aprendizagem, promovendo apenas a diversão (De Paula \& Fávero, 2016). Pode-se considerar, todavia, que tais críticas podem ser remediadas a partir da forma como a gamificação é implementada.

Fragelli (2017) descreve três experiências de gamificação no curso de fisioterapia de uma universidade brasileira. Apesar de um estranhamento inicial por parte dos aprendizes envolvidos, o engajamento foi voluntário e crescente. Os resultados encontrados apontaram que a maioria dos alunos considerou que a estratégia favoreceu a aprendizagem e todos a consideraram motivadora tanto da participação em classe quanto de estudo posterior.

Por sua vez, Laskowski e Badurowicz (2014) realizaram uma comparação intergrupos (com e sem gamificação). Os resultados apontaram maior assiduidade e realização de um maior número de tarefas pelos grupos com gamificação, contudo notas superiores nos grupos sem gamificação. É importante ressaltar que nessa experiência, foram usados apenas sistemas de pontos, medalhas e quadros de liderança. Pode-se hipotetizar que o impacto sobre os resultados poderia ser potencializado com o uso de estratégias imersivas, como a inclusão de narrativas, customização e desenvolvimento heurístico.

Considerando a necessidade de mais pesquisas envolvendo gamificação no ensino superior (Orlandi et al., 2018), realizou-se a pesquisa exposta no presente trabalho. O objetivo desta pesquisa foi avaliar a percepção de discentes sobre uma estratégia gamificada, levando em consideração seus aspectos motivacionais e seus possíveis impactos no processo de aprendizagem. Para tal a atividade em questão foi desenvolvida com duas turmas da disciplina de Psicologia e Educação Inclusiva, no 6o semestre do Curso de Psicologia da Universidade Federal do Pará, no ano de 2016, a fim de expor os estudantes a um contato com a prática do Psicólogo Escolar e Educacional, mesmo em sala de aula, simulando situações enfrentadas por um psicólogo em contexto escolar.

O desafio do projeto era criar uma atividade que usasse elementos de jogos, que tornassem a disciplina mais imersiva, e oferecessem aos alunos uma experiência como psicólogo em um contexto educacional, tendo a oportunidade de utilizar conhecimento adquirido no decorrer da graduação. Segundo Macedo e Passos (2000), as informações que são adquiridas em uma situação problema, possuem chances maiores de se tornarem significantes e de se transformarem em conhecimento adquirido, pois é dada ao aluno à oportunidade de compreender e se identificar com o conteúdo transmitido.

Uma metodologia que pode ser empregada para esse fim é chamada de Processo do Incidente que, conforme descrita por Gil (1990, como citado em Berbel, 2012), se caracteriza como a apresentação de um incidente - uma situação realista, a partir da qual deverão ser derivadas reflexões em equipe. Tais discussões devem resultar na apresentação de propostas de ação pela 
equipe, as quais recebem feedbacks docente. Esse processo permite que os discentes identifiquem as consequências de suas escolhas, construindo um estudo de caso ao passo que evoluem nos seus processos decisórios.

A proposta foi então criar um Processo do Incidente pautado na estrutura de um RPG (Role Playing Game), que em tradução literal significa "Jogo de Interpretação de Papéis". Este tipo de jogo se caracteriza pela presença de narrador chamado de "Mestre" que fica responsável por narrar uma história e os outros jogadores responsáveis pela interpretação de seus personagens de forma dramática em um cenário fictício de acordo com a proposta do Mestre.

Por ser um jogo fundamentado na interação social, Bittencourt e Giraffa (2003) sugerem que o RPG é uma excelente ferramenta para propiciar o desenvolvimento psicológico, considerando que a aprendizagem dos conteúdos apenas se consolida se o indivíduo for exposto a situações que o permitam exercitar o conhecimento adquirido. Com o aluno interessado no jogo, ele passa a procurar por ideias para a composição do seu personagem, estudar e pesquisar para suprir as lacunas que existirem na sua interpretação.

\section{MÉTODO}

\subsection{Caracterização da pesquisa}

O presente trabalho se constitui de uma pesquisa de campo, aplicada e de caráter quantitativo (Günther, 2006). Ela é considerada como de campo, pois envolve a coleta de dados em ambiente natural e não controlado; é aplicada, pois deriva e é voltada a uma atividade prática; e tem abordagem quantitativa, pois utiliza um instrumento de coleta que buscou mensurar numericamente a percepção dos participantes, bem como categorizar e quantificar a narrativa dos participantes em questões abertas.

\subsection{Participantes}

A atividade gamificada foi realizada com 52 alunos (26 alunos em cada turma) do 6응 semestre do Curso de Psicologia da Universidade Federal do Pará, que estavam cursando a disciplina: Psicologia e Educação Inclusiva - componente curricular ministrado por uma das autoras do trabalho. No final da disciplina todos os alunos foram convidados a participar da pesquisa. Aos que aceitaram foi entregue o Termo de Consentimento Livre e Esclarecido, sendo a participação opcional. O questionário foi aplicado em uma amostra de 35 alunos (20 alunos da Turma A e 15 da Turma B).

\subsection{Características da atividade gamificada}

Dentro do planejamento da disciplina foi proposto a ambas as turmas uma atividade gamificada seguindo a metodologia de Processo do Incidente, simulando um RPG. Os discentes tinham a liberdade de aceitar ou recusar a atividade, sem prejuízos na avaliação.

A turma foi dividida em 4 equipes, e cada equipe, como um todo, representava o papel de um Psicólogo em contexto educacional (foi dado às equipes a liberdade de criar o avatar de seu personagem caso quisessem). Cada equipe recebeu uma ficha fictícia de um aluno, diferenciados em deficiência (para esta atividade foram utilizadas as seguintes deficiências: autismo, cegueira, 
síndrome de Down, surdez) e contexto educacional (diferentes níveis e redes de ensino). Foram apresentadas as regras e explicado que a atividade seria dividida em quatro cenários (que corresponderiam a fases/níveis). Todos começariam no Cenário 1, porém o avanço nos cenários dependeria do ritmo e habilidades de cada equipe, e cada cenário simularia situações reais enfrentadas por psicólogos escolares. A complexidade e a dificuldade aumentariam conforme o avanço no cenário. Os quatro cenários foram: Cenário 1 - Matrícula na escola; 2 - Começo das aulas; 3 - Resultados baixos na primeira avaliação e Cenário 4 - Isolamento social. A conclusão de todos os cenários levaria à obtenção do conceito "Excelente" na disciplina, ao passo que a não conclusão de nenhum cenário deixaria a equipe com conceito de "Sem Avaliação". Entretanto o aluno que não quisesse participar da atividade poderia optar por apresentar um trabalho similar em formato de seminário, garantindo assim o caráter voluntário necessário a uma atividade gamificada.

Cada cenário possuía uma Meta a ser atingida para que os alunos o concluíssem. Cada Meta só seria alcançada através de Ações, que eram atitudes escolhidas para lidar com a situação problema. Um exemplo de como se daria o progresso dentro de um cenário está representado na Figura 1, onde os quadros da segunda coluna representam as Metas que os alunos deveriam atingir, e os quadros da terceira coluna representam as Ações possíveis dentro das Metas. Essas ações posteriormente foram analisadas segundo as Habilidades presente nelas.

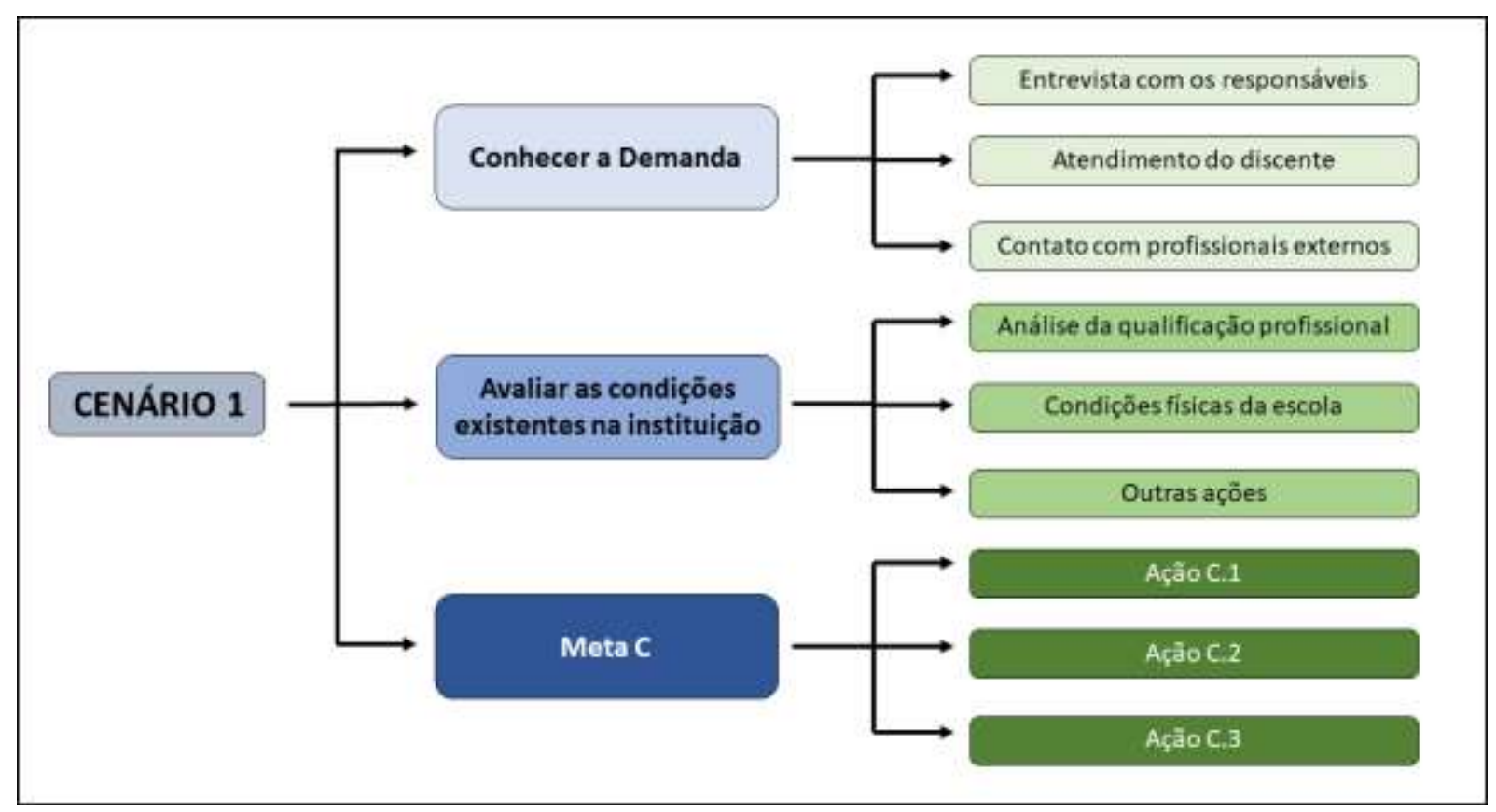

Figura 1: Fluxograma de metas e ações para cumprimento de um cenário.

De acordo com as Ações escolhidas pelo grupo seria possível avaliar as Habilidades Técnicas, Interpessoais e Analíticas, descritas por Del Prette e Del Prette (1996) e sintetizadas na Tabela 1, como necessárias para a eficácia das interações sociais de um psicólogo no contexto Escolar e Educacional.

Tabela 1: Descrição de habilidades

\begin{tabular}{c|c}
\hline Habilidades & Descrição \\
\hline Habilidades Analíticas & Identificação de elementos pertencentes ao processo educacional
\end{tabular}


Habilidades Técnicas Habilidades Interpessoais
Entrevistas, estratégias de intervenção, elaboração de documentos. Comunicação, cooperação, coordenação de grupos, assertividade.

O grupo precisava ter apenas uma Ação adequada para cada uma das Metas para poder passar de Cenário. As habilidades presentes nas Ações escolhidas pela equipe eram avaliadas e com isso era atribuído a elas uma quantidade de Experiência (XP). Os alunos também poderiam avançar de nível, conforme o acúmulo de XP (Tabela 2), e assim poderiam ganhar alguma recompensa (algo que pudesse ajuda-los na próxima fase). $\mathrm{O}$ avanço de cenário era consequência da conclusão da tarefa, enquanto o nível indicava o grau de desempenho da equipe. As equipes que chegavam ao Nível 5 ganhavam um Certificado de Mérito Acadêmico, e o acesso liberado para uma atividade acadêmica de 4 horas complementares a ser definida pelo interesse dos ganhadores. Tabela 2: Tabela de níveis e pontuação a serem
alcançados

\begin{tabular}{c|c}
\hline Número de XP & Níveis alcançados \\
\hline- & Nv. 1 \\
$150 \times p$ & Nv. 2 \\
$330 \times p$ & Nv. 3 \\
$520 \times p$ & Nv. 4 \\
$1000 \times p$ & Nv. 5 \\
\hline
\end{tabular}

Após a entrega das Metas, era dado à equipe um feedback, que se trata de uma resposta às ações do jogador, que possibilita uma confirmação ou reavaliação das ações escolhidas (Martins et al., 2014). A equipe que ficasse insatisfeita com o resultado em um cenário, poderia refazê-lo mediante aviso prévio à equipe docente, e assim poderia acumular mais XP e subir de níveis. No final da disciplina as equipes socializariam com a turma através de um seminário, falando sobre seus personagens e as ações que eles tomaram para concluir os quatro cenários.

Procurou-se, portanto contemplar todos os elementos dos jogos: metas; regras; participação voluntária; e feedback (McGonigal, 2012), sendo que a velocidade no fornecimento do feedback e a construção de uma narrativa envolvente, caracterizando com detalhes o aluno e a escola na qual o caso seria desenvolvido, foram ênfases no planejamento do processo. Além disso, a concessão de pontos e níveis de experiência, a organização das tarefas em formato de desafios e missões coerentes com as narrativas construídas, são ferramentas típicas de jogos e tendem a aumentar o engajamento nas tarefas propostas (Orlandi et al., 2018). Ao contrário do que normalmente se pressupõe em contextos de jogo, não foi estabelecido um contexto de competição intra ou intergrupos, sendo priorizadas atitudes colaborativas e socialização coletiva dos resultados.

\subsection{Materiais e instrumentos}

Para este trabalho foi elaborado um questionário semi-estruturado, formado por 20 questões fechadas, utilizando uma escala likert de 5 pontos variando de "Discordo totalmente" à "Concordo totalmente", e uma questão aberta para os participantes colocarem suas impressões 
pessoais sobre a atividade. A escala likert exige que os entrevistados indiquem seu grau de concordância ou discordância com declarações relativas à atitude que está sendo medida (Mattar, 2013).

\subsection{Análise dos Resultados}

Para analisar os itens da escala likert foi utilizado o cálculo do Ranking Médio (RM) proposto por Oliveira (2005). Neste cálculo é atribuído um valor de 1 a 5 para cada resposta a partir da qual é calculada a Média Ponderada para cada item, baseando-se na frequência das respostas. Desta forma foi obtido o RM através da seguinte equação:

Média Ponderada: (MP) $=\Sigma(\mathbf{f i}$. Vi)

Ranking Medio: $(\mathbf{R M})=\mathbf{M P} /$ (NS)

Onde, $\mathbf{f i}$ = frequência observada de cada resposta para cada item; $\mathbf{V i}$ = valor de cada resposta; e NS $=\mathrm{n}$ o de sujeitos.

Quanto mais próximo de 5 o RM estiver, maior será o nível de concordância dos estudantes com a afirmação e quanto mais próximo de 1 , menor.

Depois deste cálculo, foi ainda calculada a média aritmética entre os RM que constituem cada uma das três categorias que estavam sendo investigadas: o conhecimento acerca do tema gamificação; os aspectos motivacionais da atividade; e a assimilação do conteúdo e os objetivos da ementa. Além de ter sido analisada a média no total de alunos, também houve uma análise da média por turmas.

\section{RESULTADOS E DISCUSSÃO}

\subsection{Análise dos dados quantitativos}

Neste tópico são apresentados os resultados da pesquisa através de tabelas para cada um dos blocos de perguntas relacionadas a alguns aspectos da atividade gamificada.

A Tabela 3 apresenta o grau médio das questões relacionadas ao contato dos alunos com o conceito de gamificação e o contato com atividades gamificadas durante a graduação. O resultado $(\mathrm{RM}=1,92)$ mostra que, em média, antes da disciplina eles tinham pouco conhecimento acerca do que se tratava o tema, e que atividades que incorporem elementos dos jogos, possuem frequência baixa durante o curso.

Tabela 3: Conhecimento sobre o tema gamificação

\begin{tabular}{l|c|c|c}
\hline \multicolumn{1}{c|}{ ITEM DE AVALIAÇÃO } & \multicolumn{3}{c}{ MÉDIA } \\
\cline { 2 - 4 } & Geral & A & B \\
\hline $\begin{array}{l}\text { 1. Antes da disciplina e da atividade, você já havia conhecido algo relacionado ao } \\
\text { tema "gamificação aplicada em ambientes de aprendizagem”? }\end{array}$ & 2,14 & 2,15 & 2,13 \\
$\begin{array}{l}\text { 2. Durante a graduação você já tinha tido outras atividades que incorporassem } \\
\text { elementos dos games? }\end{array}$ & 1,71 & 1,80 & 1,60 \\
\hline \multicolumn{1}{c|}{ MÉDIA DO GRUPO } & $\mathbf{1 , 9 2}$ & $\mathbf{1 , 9 7}$ & $\mathbf{1 , 8 6}$ \\
\hline
\end{tabular}


Na Tabela 4, estão apresentados os itens referentes a aspectos motivacionais da atividade gamificada, que teve um resultado positivo com RM de 4,47. A menor média individual foi sobre o grau de dificuldade da atividade $(\mathrm{RM}=3,54)$, e as maiores médias foram dadas aos Feedbacks $(\mathrm{RM}=$ $4,88$ e 4,68 ) e o suporte dado pela professora ( $R M=4,91)$, mostrando que o auxílio do professor e feedbacks positivos ou sobre a necessidade melhorias durante o processo de aprendizagem são elementos fundamentais ao sucesso da metodologia.

Tabela 4: Aspectos motivacionais da atividade

\begin{tabular}{|c|c|c|c|}
\hline \multirow{2}{*}{ ITEM DE AVALIAÇÃO } & \multicolumn{3}{|c|}{ MÉDIA } \\
\hline & Geral & A & B \\
\hline $\begin{array}{l}\text { 1. A proposta de atividades gamificadas no processo de ensino } \\
\text { aprendizagem é interessante? }\end{array}$ & 4,65 & 4,60 & 4,73 \\
\hline 2. O caráter lúdico da tarefa é motivacional? & 4,45 & 4,30 & 4,66 \\
\hline $\begin{array}{l}\text { 3. Você se sentiu envolvido no seu processo de ensino } \\
\text { aprendizagem? }\end{array}$ & 4,25 & 3,95 & 4,66 \\
\hline 4. A atividade foi divertida e prazerosa? & 4 & 3,85 & 4,20 \\
\hline $\begin{array}{l}\text { 5. Durante a atividade, o/a professor (a) construiu um ambiente } \\
\text { favorável ao aprendizado e onde os alunos tiveram suas dúvidas e } \\
\text { pedidos de ajuda legitimados? }\end{array}$ & 4,91 & 5 & 4,80 \\
\hline $\begin{array}{l}\text { 6. O fato da nota final não ser baseada em uma avaliação, mas sim } \\
\text { na evolução dos personagens e no acumulo de pontos é } \\
\text { motivacional? }\end{array}$ & 4,68 & 4,55 & 4,86 \\
\hline $\begin{array}{l}\text { 7. A possibilidade de refazer uma fase/cenário e melhorar sua } \\
\text { pontuação é motivacional? }\end{array}$ & 4,68 & 4,55 & 4,73 \\
\hline $\begin{array}{l}\text { 8. O feedback dado após a conclusão de cada fase/cenário serviu } \\
\text { para confirmar ou reavaliar as escolhas e táticas utilizadas? }\end{array}$ & 4,88 & 4,95 & 4,80 \\
\hline $\begin{array}{l}\text { 9. O feedback dado após à execução de cada fase/cenário é mais } \\
\text { efetivo do que dado ao final da atividade? }\end{array}$ & 4,68 & 4,60 & 4,80 \\
\hline 10. A atividade gamificada foi desafiadora? & 4,54 & 4,45 & 4,66 \\
\hline 11. A atividade apresentou um alto grau de dificuldade? & 3,54 & 3,45 & 3,66 \\
\hline MÉDIA DO GRUPO & 4,47 & 4,38 & 4,59 \\
\hline
\end{tabular}

Durante a realização das atividades, os discentes nunca estavam isolados - eles tinham seus colegas de grupo para conversar, e o auxílio da professora e dos monitores da disciplina. Porém, o fato dos alunos terem que buscar informações e estratégias para alcançarem as Metas de cada Cenário acabava por fazer com que eles abandonassem a postura passiva do seu processo de 
aprendizagem, estimulando neles a autonomia, o autogerenciamento e a busca por novos conhecimentos, caracterizando um maior envolvimento com o seu processo de aprendizagem $(R M=4,25)$. Berbel (2012) relata que é pouco provável que os alunos se envolvam em todas as atividades de aprendizagem de forma espontânea, autônoma e com interesse, por isso a interação do aluno com o professor é uma das principais fontes de motivação. Ela também destaca a importância que estes busquem utilizar atividades que contenham como proposta desenvolver nos alunos a habilidade de pensar e a autonomia, substituindo situações de controle do professor sobre o aluno.

A possibilidade de refazer um cenário e aumentar sua quantidade de $\mathrm{XP}$, também teve médias altas $(\mathrm{RM}=4,68)$, demonstrando que dar maior destaque para aprendizagem e evolução do aluno pode ser um excelente substitutivo para o modelo tradicional de feedback entregue apenas no final da disciplina. Nesse modelo os alunos só podem avaliar o caminho que percorreram dias depois, após a correção do professor, e sem chance de repensar em suas ações e sem poder melhorar seu desempenho. A importância e a função do feedback já foram destacadas por Martins et al., (2014). Por sua vez, Fardo (2013) destaca que os jogos consideram o erro o principal modo de aprendizagem. A todo instante os jogadores lidam com desafios, e se não obtém sucesso neles, eles tentam de novo com outra abordagem, a falha se torna secundária. Isso ajuda a reduzir no aluno o medo de falhar.

$\mathrm{Na}$ Tabela 5 estão expostas as perguntas que investigaram se a atividade ajudou na assimilação do conteúdo conforme previsto no Projeto Político Pedagógico do Curso e na aproximação da teoria com a prática. Obteve-se aqui também uma média alta de 4,29, o que pode estar relacionado com o dado de que a atividade gamificada teve um impacto positivo no conhecimento adquirido e na aprendizagem dos alunos $(R M=4,65)$ - resultado compatível com o obtido por Fragelli (2017). A menor média individual foi referente ao fato dos alunos se sentirem razoavelmente preparados para atuarem em uma escola com necessidade de adaptá-la a pessoas com deficiência $(\mathrm{RM}=3,74)$. Apesar desse resultado não ser tão elevado, pode-se considerar positivo para uma disciplina ministrada integralmente em sala de aula. Como destaca de Quadros (2015), a gamificação pode ter favorecido a aproximação entre as habilidades desenvolvidas em sala com o que será exercido em contextos reais.

Tabela 5: Assimilação do conteúdo programático e objetivos da ementa

\begin{tabular}{|c|c|c|c|}
\hline \multirow{2}{*}{ ITEM DE AVALIAÇÃO } & \multicolumn{3}{|c|}{ MÉDIA } \\
\hline & Geral & A & B \\
\hline $\begin{array}{l}\text { A atividade gamificada proporcionou assimilação e articulação dos } \\
\text { conhecimentos teóricos, técnicos e éticos sobre a prática do } \\
\text { Psicólogo na escola? }\end{array}$ & 4,65 & 4,65 & 4,66 \\
\hline $\begin{array}{l}\text { Durante e após a atividade, você conseguiu aplicar o } \\
\text { conhecimento adquirido de forma prática, sendo capaz de } \\
\text { identificar as demandas de uma instituição escolar e planejar } \\
\text { procedimentos de intervenção? }\end{array}$ & 4,11 & 3,95 & 4,33 \\
\hline $\begin{array}{l}\text { Você aprendeu a levantar e analisar dados da estrutura } \\
\text { organizacional de uma instituição educacional? }\end{array}$ & 4,11 & 3,90 & 4,40 \\
\hline
\end{tabular}


Você se sente preparado para atuar no contexto organizacional/institucional de uma escola, de modo a adequá-la para atendimento da diversidade dos alunos e promover a inclusão social de pessoas com deficiência?

Você conseguiu compreender a evolução do processo educacional e o desenvolvimento da Psicologia Educacional, relacionando-os as mudanças históricas, sociais, políticas e econômicas ocorridas na sociedade brasileira?

Foi possível compreender e analisar criticamente a prática do psicólogo escolar e sua função como integrante de uma equipe interdisciplinar?

A atividade gamificada ajudou no seu processo de aprendizagem?

\section{MÉDIA DO GRUPO}

\begin{tabular}{|l|c|c}
3,74 & 3,65 & 3,86 \\
4,17 & 4,30 & 4 \\
4,65 & 4,65 & 4,66 \\
4,65 & 4,55 & 4,80 \\
\hline 4,29 & $\mathbf{4 , 2 3}$ & $\mathbf{4 , 3 8}$ \\
\hline
\end{tabular}

\subsection{Análise das questões abertas}

O questionário também incluiu perguntas abertas, que permitissem aos participantes destacar espontaneamente os pontos positivos e negativos da atividade gamificada e sobre a metodologia da disciplina. Os pontos mais recorrentes foram agrupados nas categorias apresentadas e discutidas a seguir.

Dentre os aspectos positivos, a aprendizagem ativa foi o mais citado pelos alunos. A aplicação de metodologias de aprendizagem ativa faz com que o aluno interaja com o assunto através da resolução de problemas e/ou planejamento de projetos (Berbel, 2012). Propor um Processo do Incidente no formato de RPG onde os alunos assumem o papel de um Psicólogo e colocá-lo para resolver problemas em um contexto escolar, por mais que seja de forma imaginária, acaba por fazer com que eles se aproximem um pouco mais da prática, do que apenas adotar aulas expositivas e com pouca aplicação. Outro ponto destacado foram as reações afetivas e emocionais dos alunos diante das atividades e de outros elementos que compõem o ambiente escolar. Esse envolvimento emocional com a experiência já havia sido destacado por Figueiredo, Paz e Junqueira (2015) e deve ser encarado como fator relevante na fixação do conhecimento e no engajamento dos alunos (Seixas, Gomes, Melo Filho \& Rodrigues, 2014; Barbosa \& Moura, 2014).

Os pontos negativos ressaltados pelos alunos fazem referência ao tempo. Devido à greve das Universidades e Institutos Federais ocorrida em 2016, o semestre precisou ser encurtado. Com isso, restaram cerca de dois meses para a conclusão da atividade. Desta forma, os alunos apontaram o limite de tempo e alta demanda de tarefas como aspectos prejudiciais da proposta.

Como sugestões, foi proposto que ao invés de apenas uma socialização feita após a conclusão de todos os cenários, ela fosse feita ao final de cada cenário. A proposta se mostra interessante e deve ser mais bem estudada para aplicações futuras. Sugeriram também que fosse aumentado o nível de competitividade entre grupos e que houvesse mais atividades gamificadas durante a disciplina, com o uso de jogos curtos nas aulas teóricas. 


\section{CONSIDERAÇÕES FINAIS}

$\mathrm{O}$ advento das tecnologias digitais mudou profundamente a relação do homem com o mundo e do homem com ele mesmo. Praticamente todas as áreas em que o ser humano atua foram modificadas de uma forma ou de outra com a introdução das tecnologias digitais (Fardo, 2013). Mudanças nas formas de comunicação e na produção de conhecimento são fundamentais para a educação dessa geração que vive imersa na cultura digital, com isso, o papel da escola também precisa de modificações, e ao invés de tratar o uso de tecnologias como obstáculos para a propagação de um saber obsoleto e inadequado, a escola deveria incorporar o uso destas tecnologias e assumir a função de orientar e ensinar os jovens a fazerem um melhor uso e aplicação das informações disponíveis (Berbel, 2012; Barbosa \& Moura, 2013; Fardo, 2013). Não apenas ensinar conteúdo, mas tornar o indivíduo apto a enfrentar as situações da vida. Estimular suas potencialidades, o senso crítico e a autonomia, fazê-los compreender e aceitar as diferenças do outro e o trabalho em equipe.

Barbosa e Moura (2013) utilizam um proverbio chinês para explicar o que é Aprendizagem Ativa: "O que eu ouço eu esqueço; o que eu vejo eu lembro; o que faço, eu compreendo". Segundo estes autores, mais do que ler, ouvir e escrever, é necessário que o aprendiz pergunte, discuta, resolva problemas e desenvolva projetos para ter uma aprendizagem mais efetiva.

Este trabalho buscou mostrar a utilização de uma atividade gamificada e analisar a efetividade do uso de elementos dos jogos para estimular o engajamento dos alunos e a aproximação deles com a prática sem sair da sala de aula. No contexto educacional, a utilização da gamificação pode promover o desenvolvimento cognitivo, aumentar a motivação dos alunos e a autonomia, por se tratar de uma proposta que exige participação ativa.

Os resultados obtidos através da análise dos questionários aplicados mostraram que a atividade proposta teve efeitos positivos no engajamento dos alunos, estimulando neles a autonomia em relação ao seu próprio processo de aprendizagem. A pesquisa também mostrou que a atividade foi positiva em aproximar os alunos com a prática do psicólogo no ambiente escolar, juntando teoria e sua aplicação. Também foi evidenciada a importância dos feedbacks dados ao longo do processo de aprendizagem, e com isso destaca-se a importância do papel do professor e de dar aos alunos a liberdade para falhar e experimentar.

Os pontos positivos superaram os negativos, sendo a autonomia e aproximação com a prática os mais destacados, além de despertar emoções e contribuir para motivação dos alunos durante a disciplina. Vivenciar a prática do psicólogo escolar por meio da imaginação pode ser uma maneira de incentivar a aproximação da prática mesmo sem sair da sala de aula.

O objetivo dessa pesquisa foi contribuir para uma educação baseada em evidências e, mais especificamente, identificar o potencial de aplicação da gamificação nas salas de aula, dando aos professores uma estratégia nova para enriquecer sua prática. Trabalhos futuros podem ser derivados deste, como a replicação da atividade em outras disciplinas/cursos, implementar melhorias ou adicionar ferramentas novas à proposta inicial, como criar um grupo de controle para fazer análise comparativa dos resultados. 
Os resultados obtidos nesta pesquisa não permitem generalizações, por terem captado a experiência de apenas dois grupos reduzidos de estudantes. Os dados coletados são também limitados por não terem sido comparados com um grupo controle. Ainda assim, indicam possibilidades de avanços na utilização da gamificação na área educacional e na aprendizagem ativa, e apontam para uma necessidade de aprofundamento de pesquisas nesta área, para que se possa validar uma estratégia adicional à prática docente.

\section{REFERÊNCIAS}

Barbosa, E. F., \& de Moura, D. G. (2013). Metodologias ativas de aprendizagem na educação profissional e tecnológica. Boletim Técnico do Senac, 39(2), 48-67.

Berbel, N. A. N. (2012). As metodologias ativas e a promoção da autonomia de estudantes. Seminário: Ciências Sociais e Humanas, 32(1), 25-40.

Bittencourt, J. R., \& Giraffa, L. M. (2003). Role-playing games, educação e jogos computadorizados na cibercultura. In l Simpósio de RPG em Educação. Recuperado de http://www.cin.ufpe.br/ jrpn/arquivos/5\%BA\%20Periodo/Metodologia/Listas/Flavia/histori apaper03.pdf.

Borges, S. D. S., Reis, H. M., Durelli, V. H., Bittencourt, I. I., Jaques, P. A., \& Isotani, S. (2013). Gamificação aplicada à educação: um mapeamento sistemático. In Simpósio Brasileiro de Informática na Educação-SBIE, 24(1), 234-243. Recuperado de http://www.brie.org/pub/index.php/sbie/article/view/2501/2160. doi: 10.5753/cbie.sbie.2013.234

Del Prette, Z. A. P., \& Del Prette, A. (1996). Habilidades envolvidas na atuação do Psicólogo Escolar/Educacional. In S. M. Wechsler (Org.), Psicologia escolar: pesquisa, Formação e prática, 139-156. Campinas: Alínea.

Diogo, M. F., Raymund, L. S., Wilhelm, F. A., de Andrade, S. P. C., Lorenzo, F. M., Rost, F. T., \& Bardagi, M. P. (2016). Percepções de coordenadores de curso superior sobre evasão, reprovações e estratégias preventivas. Avaliação: Revista da Avaliação da Educação Superior, 21(1), 125-151.

Fardo, M. L. (2013). A gamificação como estratégia pedagógica: estudo de elementos de games aplicados em processos de ensino aprendizagem. (Dissertação de mestrado defendida no Programa de Pós-Graduação em Educação da Universidade de Caxias do Sul, Caxias do Sul, RS). Recuperado https://repositorio.ucs.br/xmlui/bitstream/handle/11338/457/Dissertacao\%20Marcelo\%20L uis\%20Fardo.pdf?sequence=1.

Ferreira-Costa, R., Lima, A., Rodrigues, F., \& Galhardo, E. (2007). O Role Playing Game (RPG) como ferramenta de aprendizagem no ensino fundamental e médio. São Paulo. Recuperado de http://www.unesp.br/prograd/PDFNE2006/artigos/capitulo1/oroleplayingame.pdf.

Fiqueiredo, M., Paz, T., \& Junqueira, E. (2015). Gamificação e educação: um estado da arte das pesquisas realizadas no Brasil. In Anais dos Workshops do Congresso Brasileiro de Informática na Educação, 4(1), 1154-1163 
Fragelli, T. B. O. (2017). Gamificação como um processo de mudança no estilo de ensino aprendizagem no ensino superior: um relato de experiência. Revista Internacional de Educação Superior, 4(1), 221-233.

Fortunato, I., \& Teichner, O. T. (2017). Gamificação aplicada ao plano de aula: elementos para potencializar o ensino. Revista Eletrônica Científica Ensino Interdisciplinar, 3(9), 380-386.

Gil, E. S., Garcia, E. Y. A., Lino, F. M. A., Gil, J. L. V. (2017). Estratégias de ensino e motivação de estudantes no ensino superior. Vita et Sanitas, 6(1), 57-81.

Günther, H. (2006). Pesquisa qualitativa versus pesquisa quantitativa: esta é a questão. Psicologia: teoria e pesquisa, 22(2), 201-210.

Laskowski, M., \& Badurowicz, M. (2014). Gamification in higher education: a case study. In Management, Knowledge and Learning (MakeLearn) International Conference, 2014, 971975.

Losso, C. R. C., \& Borges, M. K. (2015). Gamificação em pesquisas em educação: uma revisão da produção acadêmica. In 20 Colóquio Internacional de Educação e Tecnologias e 6o Simpósio Hipertexto e Tecnologias na Educação. Recife: Editora da UFCE, v.1, p. 1-21.

Maluf, A. (2016) Alternativas pedagógicas: propostas para ensinar em espaços de aprendizagem. Rio de Janeiro. Wak Editora.

Martins, T. M. O. (2013) A metamorfose do modo de ser e de estar no mundo atual e as reais mudanças na sala de aula presencial. Rio de Janeiro: Revista Educação On-line PUC-Rio, 12, 150-166. Recuperado de https://www.maxwell.vrac.puc-rio.br/21609/21609.PDF

Martins, T., Nery Filho, J., Vieira, F., \& Pontes, E. (2014). A Gamificação de conteúdos escolares: uma experiência a partir da diversidade cultural brasileira. In X Seminário de Jogos Eletrônicos, Educação e Comunicação.

Mattar, F. N. (2013). Pesquisa de marketing-edição compacta (Vol. 5). Rio de Janeiro: Elsevier.

McGonigal, J. (2012). A realidade em jogo: por que os games nos tornam melhores e como eles podem mudar o mundo. Rio de Janeiro: BestSeller.

Orlandi, T. R. C., Duque, C. G., Mori, A. M., \& Orlandi, M. T. D. A. L. (2018). Gamificação: uma nova abordagem multimodal para a educação. Biblios: Revista electrónica de bibliotecología, archivología y museología, 70, 18-30.

Pelling, N. (2011). The (short) prehistory of gamification. Recuperado de http:// nanodome.wordpress.com/2011/08/09/the-shortprehistory-of-gamification/

Quinaud, A. L., \& Baldessar, M. J. (2017). A educação no século XXI: gamificação aprendizagem com criatividade. Temática, 13(11), 215-228.

Quadros, G. B. F. de (2015). In Anais do Encontro Virtual de Documentação em Software Livre e Congresso Internacional de Linguagem e Tecnologia Online, 4(1), 1-6. 
Seixas, L. R., Gomes, A. S., Melo Filho, I. J., \& Rodrigues, R. L. (2014). Gamificação como Estratégia no Engajamento de Estudantes do Ensino Fundamental. In Simpósio Brasileiro de Informática na Educação-SBIE, 5(1), 559-568. Recuperado de $\underline{\mathrm{http}: / / \mathrm{br}-}$ ie.org/pub/index.php/sbie/article/view/2985/2496. 